\title{
Carica papaya extract in dengue: a systematic review and meta-analysis
}

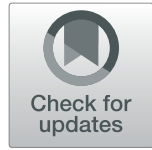

\author{
Senaka Rajapakse ${ }^{1 *}$ D N Nipun Lakshitha de Silva ${ }^{2}$, Praveen Weeratunga ${ }^{1}$, Chaturaka Rodrigo ${ }^{3}$, \\ Chathurani Sigera ${ }^{4}$ and Sumadhya Deepika Fernando ${ }^{4}$
}

\begin{abstract}
Background: Carica papaya (CP) extract is becoming popular as an unlicensed herbal remedy purported to hasten recovery in dengue infection, mostly based on observations that it may increase platelet counts. This systematic review and meta-analysis aims to critically analyze the evidence from controlled clinical trials on the efficacy and safety of CP extract in the treatment of dengue infection.

Methods: PubMed, LILACS and Google Scholar were searched for randomized or non-randomized trials enrolling patients with suspected or confirmed dengue where CP extract was compared, as a treatment measure, against standard treatment. Recovery of platelet counts as well as other clinical indicators of favourable outcome (duration of hospital stay, prevention of plasma leakage, life threatening complications, and mortality) were assessed.
\end{abstract}

Results: Nine studies (India-6, Pakistan-1, Indonesia-1, Malaysia-1) met the inclusion criteria. Seven studies showed an increase in platelet counts in patients receiving CP extract, while one study showed no significant difference between the two groups, and direct comparison was not possible in the remaining study. Serious adverse events were not reported. CP extract may reduce the duration of hospital stay (mean difference -1.98 days, 95\% confidence interval -1.83 to $-2.12,3$ studies, 580 participants, low quality evidence), and cause improvement in mean platelet counts between the first and fifth day of treatment (mean difference 35.45, 95\% confidence interval 23.74 to $47.15,3$ studies, 129 participants, low quality evidence). No evidence was available regarding other clinical outcomes.

Conclusions: The clinical value of improvement in platelet count or early discharge is unclear in the absence of more robust indicators of favourable clinical outcome. Current evidence is insufficient to comment on the role of $\mathrm{CP}$ extract in dengue. There is a need for further well designed clinical trials examining the effect of CP on platelet counts, plasma leakage, other serious manifestations of dengue, and mortality, with clearly defined outcome measures.

Keywords: Dengue, Thrombocytopaenia, Carica papaya, Papaya leaf extract

\section{Introduction}

Dengue is an arboviral infection transmitted by mosquitoes of the Aedes species. It is a disease with global implications, resulting in considerable morbidity and mortality. Transmission occurs in at least 128 countries, and almost 4 billion people are at risk [1]. Data from the Global Burden of Disease Study 2013 showed that the incidence of dengue has markedly increased over the

\footnotetext{
* Correspondence: senaka@med.cmb.ac.lk

'Department of Clinical Medicine, Faculty of Medicine, University of

Colombo, 25, Kynsey Road, Colombo 8, Colombo, Sri Lanka

Full list of author information is available at the end of the article
}

years, from 8.3 million cases in 1990 to a staggering 58.4 million cases in 2013 [2]. The annual average number of deaths due to dengue from 1990 to 2013 was estimated at 9221 . It is currently estimated that around 390 million dengue infections occur annually, and that 96 million of these result in clinical disease [3]. South and South East Asia account for a major proportion of the global burden of dengue, with an estimated mortality of 8.49 per million population in 2013 [2].

Dengue fever occurs due to infection by four distinct serotypes (DEN 1-4), and has diverse manifestations, ranging from an uncomplicated febrile illness to serious

(c) The Author(s). 2019 Open Access This article is distributed under the terms of the Creative Commons Attribution 4.0 International License (http://creativecommons.org/licenses/by/4.0/), which permits unrestricted use, distribution, and reproduction in any medium, provided you give appropriate credit to the original author(s) and the source, provide a link to the Creative Commons license, and indicate if changes were made. The Creative Commons Public Domain Dedication waiver (http://creativecommons.org/publicdomain/zero/1.0/) applies to the data made available in this article, unless otherwise stated. 
disease with organ dysfunction. In the more severe forms, plasma leakage gives rise to shock and organ failure; life threatening haemorrhage can also occur. Unusual organ manifestations of dengue are also increasingly reported, and comprise the expanded dengue syndrome [4]. Mortality in dengue is most often due to shock, intractable multi-organ dysfunction, or uncontrollable bleeding. Excessive fluid therapy is also known to contribute to mortality in patients with plasma leakage, due to the development of pulmonary oedema during the recovery phase.

Despite many years of extensive research, specific therapeutic modalities for dengue remain in their infancy. Immunosuppression, in the form of corticosteroids [5] or immunoglobulins, [6] has not shown benefit. Several antiviral agents and other host immune modulators are in the early stages of clinical evaluation, and will not be available for clinical use in the foreseeable future [7]. Several dengue vaccines are in development, and some already licensed for use, but these do not show convincing evidence of benefit across all age groups, and do not confer immunity for all serotypes [8]. The mainstay of clinical treatment of dengue is careful fluid management, with close monitoring and supportive care.

The lack of effective therapeutic interventions for dengue has created interest in alternative therapies, i.e., natural and herbal remedies for the disease. Carica papaya (CP) leaf extract has recently gained interest in the treatment of dengue, particularly in social media networks, and has shown increasing off-label use in the disease. While the simple extract of papaya leaves is commonly used, there are some commercial preparations containing papaya leaf extract available in certain countries.

$\mathrm{CP}$ is a ubiquitous flowering plant in the tropics, with an edible fruit. Originally native to Mexico and South America, it has flourished after introduction to South and South-East Asian countries. The leaves of the plant contain several biologically active compounds, such as papain, caricain, chymopapain, and glycine endopeptidase. These compounds have been shown to improve acidic $\mathrm{pH}$, and cause degradation of pepsin [9]. $\mathrm{CP}$ also contains lipase, which is bound to the water-insoluble component of papain [10]. CP leaf extract has been purported to have anti-viral and haematological effects which might have pathophysiological implications for its use as treatment for dengue, such as anti-oxidant and free radical scavenging properties, [11] and improved red cell membrane stabilization [12]. The flavonoids of $\mathrm{CP}$ leaf extract have been shown to inhibit a protease involved in viral assembly [13].

During recent epidemics, patients have resorted to the off-label use of CP extract in dengue infection. However intense debate continues regarding the therapeutic efficacy and safety profile of this treatment. This systematic review and meta-analysis aims to critically analyze the available clinical evidence from prospective controlled clinical trials on the efficacy and safety of $\mathrm{CP}$ extract in the treatment of dengue infection.

\section{Methods \\ Eligibility criteria}

We included prospective clinical trials (randomized or non-randomized) with a control group (placebo or no treatment).

\section{Information sources and search strategy}

We searched PubMed, LILACS and Google Scholar for relevant articles. PubMed and LILACS were searched with the keywords 'dengue' in any field and 'papaya' in any field without any language, time, or other restrictions. A Google Scholar search was performed with the keywords 'dengue' and 'papaya' in the title of the article with no other restrictions. References provided in full papers were also used to identify additional papers for review. The last date of the search was 2nd August 2019. We used the software Endnote X7 (Thomson Reuters, Carlsbad, CA 92011, USA) to filter articles. Review Manager (RevMan) version 5 (Cochrane Collaboration) was used to analyze the data.

\section{Study selection and data collection}

SR, PW, NLdS and CR independently screened the abstracts and selected articles reporting controlled studies. Eligible studies were finalized by consensus among all authors.

\section{Outcomes and data items extracted}

Data from individual studies were extracted using a customized data extraction proforma designed by the authors. The data items extracted from each eligible study included: location of the trial, participant demographics, patient characteristics of test and control groups, severity of disease, details of interventions, and outcome measures.

\section{Selected outcomes}

We chose the following outcome measures: mortality, incidence of plasma leakage, shock, minor and major bleeding manifestations, organ complications, changes in platelets counts, haematocrit as surrogate measure of plasma leakage, days of hospitalization, transfusion requirements, need for intensive care, and safety outcomes.

\section{Risk of bias}

We assessed the risks of bias of included studies qualitatively using the Cochrane risk of bias assessment tool [14]. 

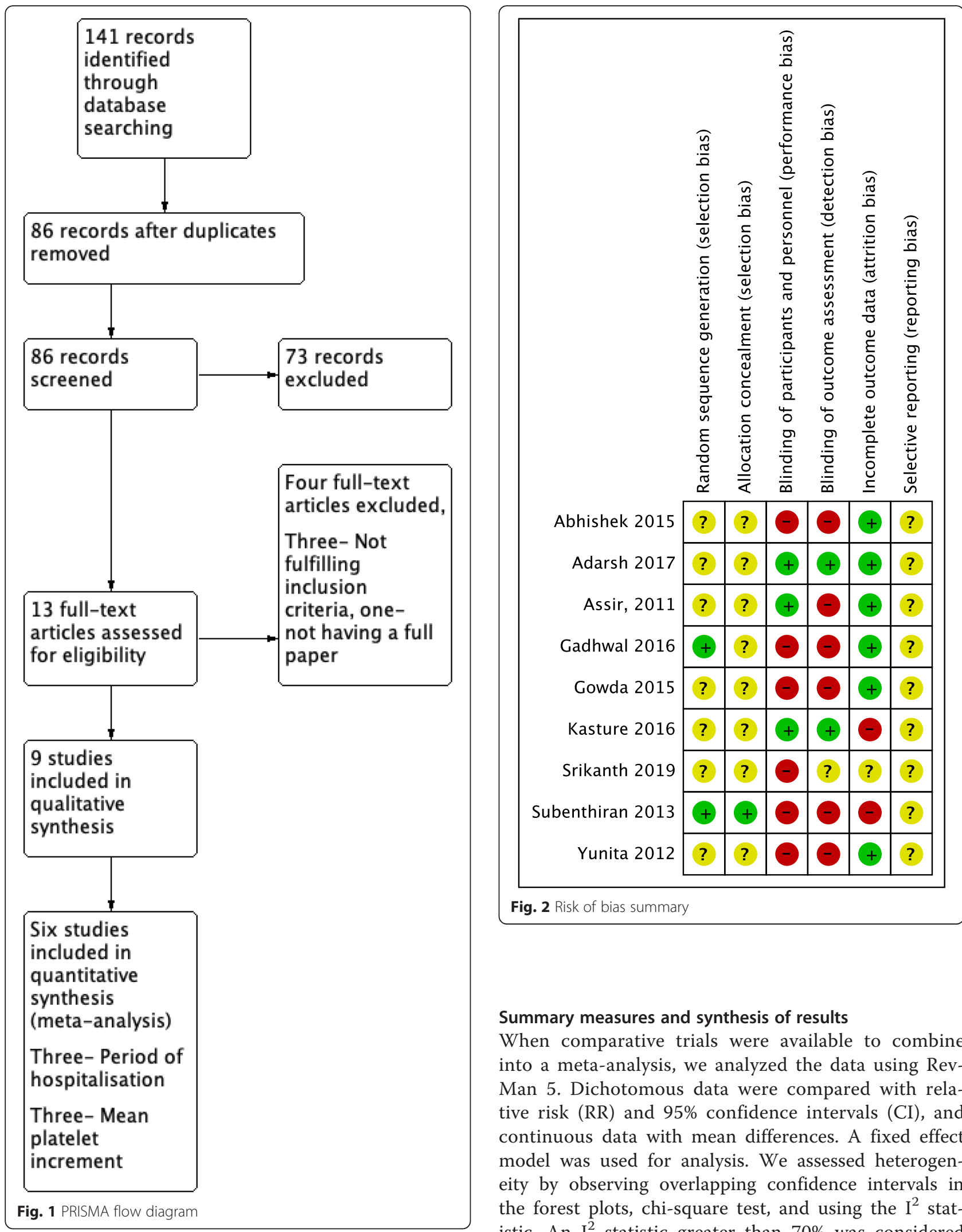

Fig. 2 Risk of bias summary

Summary measures and synthesis of results

When comparative trials were available to combine into a meta-analysis, we analyzed the data using RevMan 5. Dichotomous data were compared with relative risk (RR) and 95\% confidence intervals (CI), and continuous data with mean differences. A fixed effect model was used for analysis. We assessed heterogeneity by observing overlapping confidence intervals in the forest plots, chi-square test, and using the $\mathrm{I}^{2}$ statistic. An $\mathrm{I}^{2}$ statistic greater than $70 \%$ was considered as a high level of heterogeneity, and a random effect model was used for the analysis. 
Table 1 Summary of included studies

\begin{tabular}{|c|c|c|c|c|c|}
\hline Study & Methods & Participants & Interventions & Outcomes & $\begin{array}{l}\text { Adverse } \\
\text { events }\end{array}$ \\
\hline $\begin{array}{l}\text { Assir et al. } \\
\text { [15], } 2011\end{array}$ & $\begin{array}{l}\text { Randomized single } \\
\text { blind placebo } \\
\text { controlled study }\end{array}$ & $\begin{array}{l}\text { Patients }>14 \text { years with DF } \\
\text { or DHF with platelet }<50 \times \\
10^{9}(19 \text { intervention, } 20 \\
\text { control })\end{array}$ & $\begin{array}{l}\text { CP leaf extract syrup } \\
5 \mathrm{ml} \text { twice a day for } \\
\text { four days }\end{array}$ & $\begin{array}{l}\text { Mean platelet count increments } \\
\text { after } 2-4 \text { days were not statistically } \\
\text { significant between the two groups. } \\
\text { Mean platelet increment between } \\
\text { day } 5(4 \text { days after intervention) } \\
\text { and baseline was } 106 \pm 69.16 \text { in the } \\
\text { intervention group and } 82.3 \pm \\
37.28 \text { in the control group, and not } \\
\text { statistically significant. }\end{array}$ & $\begin{array}{l}\text { No significant } \\
\text { adverse effects } \\
\text { with CP }\end{array}$ \\
\hline
\end{tabular}

Yunita et al. Randomized open- Patients 15-55 years with [16], 2012 label controlled study suspected DF (40 in each arm)

Subenthiran Randomized open Patients 18-60 years with et al. [17], 2013 label controlled study DF or DHF with platelet < $100 \times 10^{9}(145$ in each arm $)$

Abhishek et al. [18], 2015

Randomized open

Patients 18-60 years with label controlled study

DF or DHF I, II with platelet count $30-100 \times 10^{9}(30$ in each arm)

Gowda et al. [19], 2015

Randomized, open label controlled study

Patients 18-60 years with DF or DHF I, II with platelet count $30-100 \times 10^{9}(14$ intervention group, 16 control group)

Gadhwal Randomized et al. [20], 2016 controlled study

Kasture et al. [21], 2016

Randomized double blind placebo controlled study

Adarsh et al. [22], 2017

Randomized double blind placebo controlled study
Patients $>16$ years with DF and platelet count $<150 x$ $10^{9}$ (200 in each group)
CP leaf extract capsul $1100 \mathrm{mg}$ three times a day

Fresh juice from $50 \mathrm{~g}$ of CP leaves daily for three days

CP leaf extract tablets $1100 \mathrm{mg}$ three times a day for five days
CP leaf extract tablets $1100 \mathrm{mg}$ three times a day for five days

CP leaf extract capsule 500 mg once daily for five days
Platelet counts rise more rapid in the intervention group $(p<0.05)$.

Haematocrit changes not significant. Period of hospitalization shortened with treatment. Intervention group $3.48 \pm 0.6$ days, Control group $5.38 \pm 0.67$ days $(p<0.05)$.

Mean difference in platelet count at $8 \mathrm{~h}$ and after $40 \mathrm{~h}$ : intervention group - $16.764(-24.566,-8.964)$ $p<0.001$, control group -7.703 $(-14.055,1.351)(p=0.018)$.

Mean platelet count after five days: intervention group $110.71+30.57$ control group $75.63+22.49$. Mean difference in platelet count from day 1 to day $5: 39.89+38.50$ in the intervention group, $0.71+24.76$ in the

control group, $p=0003$.

Mean platelet count on day 5 intervention group $104.71 \pm 30.57$, control group $66.63 \pm 22.49$. Mean difference in platelet count from day 1 to day 5: intervention group $39.92 \pm 38.51$, control group $00.69 \pm 24.75, p=0003$.

Mean platelet count was higher in the

intervention group from 3rd to 5th day. Average hospitalization period: intervention group $3.65 \pm$ 0.97 days, control group $5.42 \pm$ $0.98, p<0.01$. Platelet transfusion requirements: intervention group 55/200, control group 93/200.

Median platelet count on day three: intervention group 88.89, control group 55.63; on day four 102.57 and 64.58; on day five 155.88 and 70.52 , respectively. White cell count also increased in the intervention group. No difference in haematocrit.

Average platelet count was higher in the intervention group on day 3,4 and $5(p<0.01)$. Platelet transfusion requirements: intervention group $28 \%$, control group $46 \%(p<0.01)$. White cell count increased in the intervention group. Haematocrit did not show significant difference. Duration of
Not reported

Not reported

Not reported

Not reported

No side effects reported with

$\mathrm{CP}$

Nausea,

vomiting

Nausea, vomiting capsules $500 \mathrm{mg}$ three times a day for five days 
Table 1 Summary of included studies (Continued)

\begin{tabular}{|c|c|c|c|c|c|}
\hline Study & Methods & Participants & Interventions & Outcomes & $\begin{array}{l}\text { Adverse } \\
\text { events }\end{array}$ \\
\hline & & & & $\begin{array}{l}\text { hospitalization: intervention group } \\
3.45 \pm 0.98 \text {, control group } \\
6.42 \pm 0.98 \text { ( } p<0.01) \text {. }\end{array}$ & \\
\hline $\begin{array}{l}\text { Srikanth et al. } \\
\text { [23], } 2019\end{array}$ & $\begin{array}{l}\text { Randomized open } \\
\text { label controlled study }\end{array}$ & $\begin{array}{l}\text { Paediatric patients }(1-12 \\
\text { years) with DF or DHF } \\
\text { grades I or II with platelet } \\
\text { count } 30-100 \times 10^{9} \text { ( } 145 \\
\text { intervention, } 140 \text { control) }\end{array}$ & $\begin{array}{l}\text { CP leaf extract syrup } \\
275 \mathrm{mg} \text { three times } \\
\text { a day ( } 1-5 \text { years age }) \\
\text { or } 550 \mathrm{mg} \text { three times } \\
\text { a day (> } 5 \text { years) }\end{array}$ & $\begin{array}{l}\text { Increase in platelet } \\
\text { count on day } 03,04 \\
\text { and } 05 \text { were statistically } \\
\text { significant ( } p<0.05) \text {. } \\
\text { Increase in red cell } \\
\text { count was statistically } \\
\text { significant on day } 05 \text { and } \\
\text { white cell count statistically } \\
\text { significant on day } 3,4 \text { and } 5 \text {. }\end{array}$ & $\begin{array}{l}\text { Nausea in two } \\
\text { patients }\end{array}$ \\
\hline
\end{tabular}

CP Carica papaya, DF dengue fever, DHF dengue haemorrhagic fever

\section{Results}

The initial search yielded 36 results from PubMed, 72 results from Google Scholar and 33 from LILACS. After removing duplicates, 86 abstracts were left for review. The PRISMA flow diagram is shown in Fig. 1, and depicts the process of selecting studies for the systematic review and meta-analysis. After screening of abstracts, 13 potential papers were identified. After excluding three studies which did not fulfill inclusion criteria and one study where the full paper could not be obtained despite repeated attempts to contact the authors, 9 papers remained. Nine full text articles were selected for qualitative analysis and only six were selected for quantitative analysis. Fig. 2 summarizes the review authors' judgments about each risk of bias item for included studies. Assessment of each study with regards to selection bias, performance bias, detection bias, attrition bias and reporting bias is summarized. Risk of bias is graded as low risk, high risk and unclear risk. A summary of all studies is provided in Table 1 . In brief, all studies but three were conducted in India (Pakistan-1, Indonesia-1, Malaysia-1). All studies were mentioned as randomized but seven did not specify the method of random allocation. All the studies recruited young adults or adults (age range 15-60 years) except one which included only paediatric patients (age range 1-12 years). Two studies were double blind and one was single blind.

One of the earliest randomized trials comes from Pakistan, where the effect of CP leaf extract on platelet counts was studied in 39 patients with DF or DHF [15]. The diagnosis of DF was based on WHO definitions, and only patients with platelet count $<50 \times 10^{9} / \mathrm{L}$ were included, but inclusion and exclusion criteria were not well defined, and measures to minimize bias were not described. Increments in mean platelet counts daily and at the end of intervention were similar in those treated with $\mathrm{CP}$ and controls.

A randomized open-label controlled study from Indonesia tested the effect of $\mathrm{CP}$ leaf extract capsule (CPC) in patients with dengue fever [16]. Patients in the intervention group were treated with CPC $550 \mathrm{mg}$ two capsules three times a day. Outcome measures were rise in platelet count, change in haematocrit, and period of hospitalization. The method of randomization and patient selection, and the day of inclusion, were not clearly described in this study. This study shows many methodological flaws that can increase the risk of bias, and in particular, the diagnosis of dengue was based on clinical grounds (fever, thrombocytopaenia and haemoconcentration) without laboratory confirmation. Platelet counts rose more rapidly in the intervention group (day 3) compared to the control group (day 5), and platelet counts on day 3 were significantly higher in the intervention group than counts on day 5 in the control group. Haematocrit values were similar in both groups. The period of hospitalization was shorter in the intervention group compared to the control group (3.48 \pm 0.6 days vs. $5.38 \pm$ 0.67 days, $p<0.05$ ).

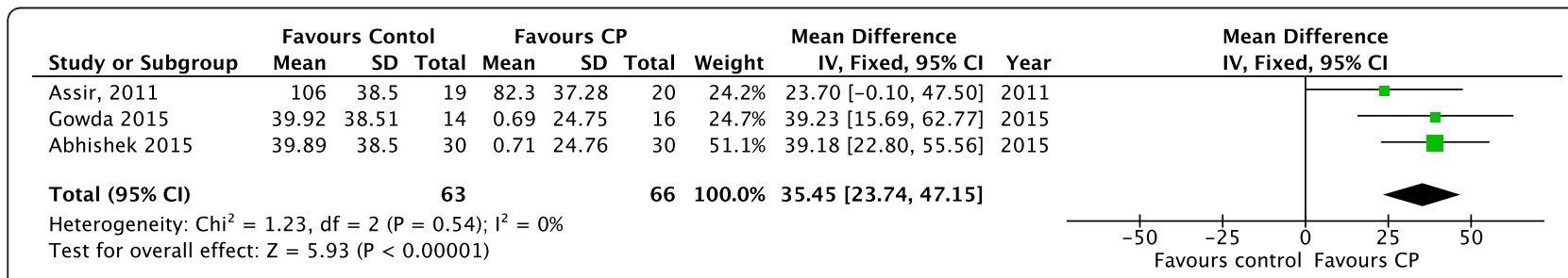

Fig. 3 Forest plot of three studies comparing mean difference of platelet count between fifth and first day between two groups 
An open-label randomized controlled study from Malaysia assessed the mean platelet count difference in dengue patients after treating with CP leaf extract juice for three days [17]. Although 145 patients were included in each group, only $111(\mathrm{CP})$ and 119 (controls) patients completed the study, increasing the risk of attrition bias. The study methodology was otherwise sound and well described, indicating measures to minimize bias in selection and randomization. Baseline mean platelet counts were similar in the two groups. Mean platelet counts from $8 \mathrm{~h}$ up to $40 \mathrm{~h}$ were not significantly different between the two groups. However at $40 \mathrm{~h}$ those who received CP had significantly higher platelet counts.

A randomized controlled study from India investigated the effect of CP leaf extract tablets on mean platelet counts in patients with DF and mild DHF [18]. In this study, the method of randomization, study participant selection, and day of febrile illness on which the intervention was started were not described. Mean platelet counts five days after commencing treatment rose in the intervention group compared to the control group (mean difference in platelets $39.89+38.50 \times 10^{9} / \mathrm{L}$ in the intervention group vs. $0.71+24.76 \times 10^{9} / \mathrm{L}$ in the control group, $p=0.003$ ).

Another open-label randomized controlled study from India assessed the effect of $\mathrm{CP}$ leaf extract tablets on platelet counts in patients with dengue [19]. The method of randomization and exact selection methodology was not described in the study. Mean platelet counts on day 5 after treatment rose in the intervention group compared to controls.

In a larger open-label randomized controlled study from India, 400 patients were randomized to assess the effect of a lower dose of CPC in DF patients [20]. Simple randomization (odd-even method) was used. Apart from mean platelet counts, the other outcome measures were period of hospitalization and platelet transfusion. The indications for platelet transfusion were platelet count $<$ $20 \times 10^{9} / \mathrm{L}$, bleeding tendency, and platelet count $<30 \times$ $10^{9} / \mathrm{L}$ with decreasing trend. From the third day onwards, mean platelet counts were higher in the intervention group (day 3: CP $82.96 \pm 16.72 \times 10^{9} / \mathrm{L}$, controls $66.45 \pm 17.36 \times 10^{9} / \mathrm{L}, \quad p<0.01$; day $4:$ CP $122.43 \pm$ $19.36 \times 10^{9} / \mathrm{L}, \quad$ controls $88.75 \pm 21.65 \times 10^{9} / \mathrm{L}, \quad \mathrm{p}<0.01$; day 4: $\mathrm{CP} \quad 122.43 \pm 19.36 \times 10^{9} / \mathrm{L}$, controls $88.75 \pm$ $21.65 \times 10^{9} / \mathrm{L}, \mathrm{p}<0.01$; day 5: CP $112.47 \pm 17.49 \times 10^{9} / \mathrm{L}$ controls $\left.102.59 \pm 19.35 \times 10^{9} / \mathrm{L}, \quad \mathrm{p}<0.01\right)$. The mean period of hospitalization, and platelet transfusion requirements, were lower in those treated with $\mathrm{CP}$.

The first double-blind placebo controlled study on CP in DF was a multicenter trial from India [21]. The methods of randomization and selection were not described. Outcome measures were changes in platelet counts, white cell counts, red cell counts and haematocrit. Median values for platelet counts in the CP group on third, fourth and fifth days were $88.897 \times 10^{9} / \mathrm{l}$, $102.579 \times 10^{9} / \mathrm{L}$ and $155.886 \times 10^{9} / \mathrm{L}$, respectively. In the control group, median platelet counts were $55.633 \times 10^{9} /$ $\mathrm{L}, 64.582 \times 10^{9} / \mathrm{L}$ and $70.528 \times 10^{9} / \mathrm{L}$ respectively. White cell counts were also higher in the CP group. Haematocrit and red cell counts were similar in the two groups.

Another double-blind randomized controlled study from India evaluated the effects of CP leaf extract in DF [22]. This study also does not provide adequate information on methods to minimize bias. Outcome measures included platelet counts and other haematological parameters, duration of hospital stay, and platelet transfusion requirements. Platelet counts were higher in the $\mathrm{CP}$ group from the third to fifth day $(p<0.01)$. Similarly, white cell counts were higher in the CP group $(p<0.01)$. Haematocrit values were similar in the two groups. Platelet transfusions were according to WHO guidelines, and platelets were transfused in $28 \%$ of patients in the intervention group and $46 \%$ in the control group $(\mathrm{p}<$ 0.01 ). The period of hospitalization was longer in the control group $(\mathrm{p}<0.01)$.

In a recent open-label randomized controlled study, the effect of CP leaf extract syrup was studied in 285 dengue patients aged less than 2 years [23]. Information on measures to minimize bias was limited. Although nine patients were excluded from efficacy analysis, reasons for this were given for only two. The primary outcome measure was mean increase in platelet count, while changes in red and white cells were taken as secondary outcome measures. Mean platelet counts were higher in the intervention group compared to the control group $(p<0.05)$.

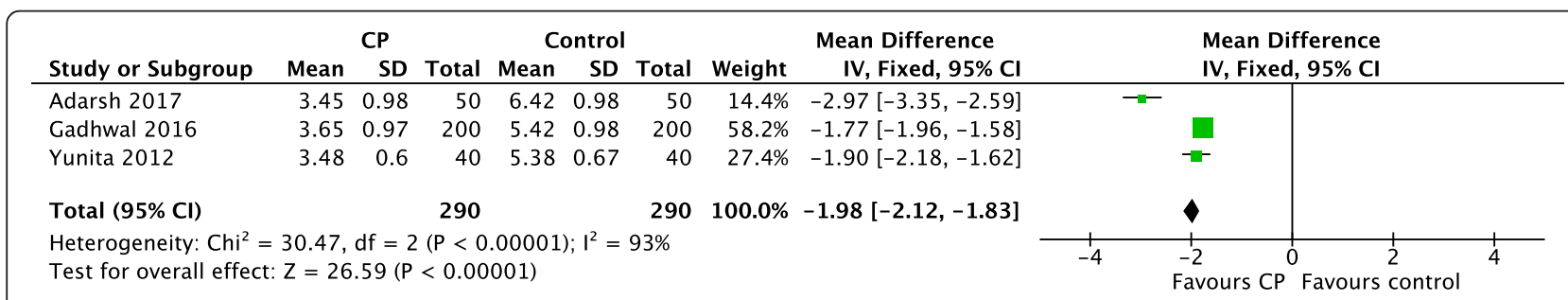

Fig. 4 Forest plot of three studies comparing period of hospitalization between two groups 
Meta-analysis for the outcome measure of platelet recovery was possible for only three studies $[15,18,19]$ (Fig. 3), because of heterogeneous methods used to determine platelet recovery, and inadequate data provided in other studies. Mean rise in platelets between the first and fifth days was significantly higher in the intervention group (mean difference 35.45, 95\% confidence interval 23.74 to $47.15,129$ participants, low quality evidence).

Three studies, involving 580 patients, also provided sufficient data on the duration of hospital stay [16, 20, 22] (Fig. 4). Pooled analysis showed that hospital stay was reduced in patients receiving papaya extract compared to either placebo or no treatment (Mean difference -1.98 days, $95 \%$ confidence interval - 1.83 to 2.12, 290 participants, low quality evidence).

Five studies reported on adverse events; three studies reported nausea and vomiting, [21-23] and two reported that there were no adverse events seen [15, 20]. The other studies did not mention details of adverse events.

\section{Discussion}

Overall, considerable heterogeneity exists in controlled trials of CP extract in dengue published so far. There are marked variations in the enrollment criteria, categorization of patients, and measurements used to determine effects on platelet counts. Studies are mostly of low to moderate quality, with high risk of bias. The doses of CP used are variable, and no attempts have been made to determine effective dose. There are ethical concerns regarding the use of CP leaves or leaf extract without formal phase I testing, as while the fruits are edible, leaves are not routinely ingested. Nonetheless, extracts of CP leaves have not been shown to contain overtly toxic substances [911]., and comparative studies do not report significant adverse events with $\mathrm{CP}$ extract.

Given these limitations, there is some evidence of beneficial effects of $\mathrm{CP}$ in patients with dengue in reducing overall hospital stay. Platelet counts appear to improve more rapidly following treatment with $\mathrm{CP}$, and in several studies the platelet counts at day 3-5 seem to be higher in those who received CP compared to those who did not. The shorter duration of hospital stay may be linked to improvement in platelet counts as well as clinical improvement, although the details of other parameters which might have prompted early discharge in these patients have not been studied in depth in any of the studies.

No studies examined the impact on mortality with CP. The effect of CP on the development or improvement of plasma leakage and haemorrhage has also not been studied, and the studies are either underpowered, or not designed with these important complications as outcome measures. In clinical practice, platelet levels correlate only loosely with the more dreaded complication of plasma leakage and shock syndrome, and the real test of efficacy of any therapeutic modality would be their effect on these life-threatening complications.

Nonetheless, there appears to be sufficient evidence from basic sciences research, and from current comparative clinical trials to justify conducting a large scale randomized double-blind placebo controlled trial to evaluate the potential benefits of CP extract. Such a trial should be designed, and powered, to determine the effects on $\mathrm{CP}$ on the following: preventing plasma leakage (for which platelet count changes may be a surrogate marker), prevention (or amelioration) of shock and multi-organ dysfunction, requirements for blood and blood product transfusion, the need for ICU admission, and the duration of ICU and hospital stay.

\section{Conclusions}

Current clinical evidence on the beneficial effects of Carica papaya extract in the treatment of dengue infection is limited, and is based on a few trials of low to moderate quality. Improvements in platelet counts and reduction in hospital stay have been demonstrated, however significant methodological flaws in many of the studies makes it difficult to make clear recommendations. The routine use of $\mathrm{CP}$ extract for treating dengue cannot be recommended based on current available evidence.

\section{Acknowledgements \\ None.}

Authors' contributions

SR, PW and SDF conceptualized this review. SR, PW, CR and NLdS performed the literature searches and identified studies for inclusion. All authors were involved in data extraction; SR, PW, CS and NLdS performed the meta-analysis. All authors were involved in writing the manuscript, and have read and approved the final manuscript.

\section{Funding \\ Funding assistance provided by University of Colombo Research Grant No: $\mathrm{AP} / 3 / 2 / 2017 / \mathrm{CG} / 25$ is gratefully acknowledged.}

Availability of data and materials

The datasets used and/or analysed during the current study are available from the corresponding author on reasonable request.

Ethics approval and consent to participate

Not required.

Consent for publication

Not required.

Competing interests

The authors declare that they have no competing interests.

\section{Author details}

${ }^{1}$ Department of Clinical Medicine, Faculty of Medicine, University of Colombo, 25, Kynsey Road, Colombo 8, Colombo, Sri Lanka. ²Department of Clinical Medicine, Faculty of Medicine, General Sir John Kotelawela Defence University, Rathmalana, Sri Lanka. ${ }^{3}$ Department of Pathology, School of Medical Sciences, University of New South Wales, Sydney, NSW, Australia. 
${ }^{4}$ Department of Parasitology, Faculty of Medicine, University of Colombo, Colombo, Sri Lanka.

Received: 1 May 2019 Accepted: 9 September 2019

Published online: 11 October 2019

\section{References}

1. Brady OJ, Gething PW, Bhatt S, Messina JP, Brownstein JS, Hoen AG, Moyes CL, Farlow AW, Scott TW, Hay SI. Refining the global spatial limits of dengue virus transmission by evidence-based consensus. PLoS Negl Trop Dis. 2012; 6(8):e1760.

2. Stanaway JD, Shepard DS, Undurraga EA, Halasa YA, Coffeng LE, Brady OJ, Hay SI, Bedi N, Bensenor IM, Castañeda-Orjuela CA, et al. The global burden of dengue: an analysis from the global burden of disease study 2013. Lancet Infect Dis. 2016;16(6):712-23.

3. Bhatt $\mathrm{S}$, Gething PW, Brady OJ, Messina JP, Farlow AW, Moyes CL, Drake JM, Brownstein JS, Hoen AG, Sankoh O, et al. The global distribution and burden of dengue. Nature. 2013;496(7446):504-7.

4. Rajapakse S, Wattegama M, Weeratunga P, Sigera PC, Fernando SD. Beyond thrombocytopaenia, haemorrhage and shock: the expanded dengue syndrome. Pathogens and Global Health. 2018;112(8):404-14.

5. Rajapakse S, Rodrigo C, Maduranga S, Rajapakse AC. Corticosteroids in the treatment of dengue shock syndrome. Infection and drug resistance. 2014;7: $137-43$.

6. Rajapakse S. Intravenous immunoglobulins in the treatment of dengue illness. Trans R Soc Trop Med Hyg. 2009:103(9):867-70.

7. Lee TH, Lee LK, Lye DC, Leo YS. Current management of severe dengue infection. Expert Rev Anti-Infect Ther. 2017;15(1):67-78.

8. Hadinegoro SR, Arredondo-García JL, Capeding MR, Deseda C, Chotpitayasunondh T, Dietze R, Hj Muhammad Ismail HI, Reynales $\mathrm{H}$, Limkittikul K, Rivera-Medina DM, et al. Efficacy and long-term safety of a dengue vaccine in regions of endemic disease. N Engl J Med. 2015;373(13): 1195-206.

9. Huet J, Looze Y, Bartik K, Raussens V, Wintjens R, Boussard P. Structural characterization of the papaya cysteine proteinases at low pH. Biochem Biophys Res Commun. 2006;341(2):620-6.

10. Dominguez de Maria P, Sinisterra JV, Tsai SW, Alcantara AR. Carica papaya lipase (CPL): an emerging and versatile biocatalyst. Biotechnol Adv. 2006; 24(5):493-9.

11. Okoko T, Ere D. Reduction of hydrogen peroxide-induced erythrocyte damage by Carica papaya leaf extract. Asian Pac J Trop Biomed. 2012;2(6): 449-53.

12. Ranasinghe $P$, Ranasinghe $P$, Abeysekera WP, Premakumara GA, Perera YS, Gurugama P, Gunatilake SB. In vitro erythrocyte membrane stabilization properties of Carica papaya L. leaf extracts. Pharm Res. 2012;4(4):196-202.

13. Senthilvel P, Lavanya P, Kumar KM, Swetha R, Anitha P, Bag S, Sarveswari S, Vijayakumar V, Ramaiah S, Anbarasu A. Flavonoid from Carica papaya inhibits NS2B-NS3 protease and prevents dengue 2 viral assembly. Bioinformation. 2013;9(18):889-95.

14. Higgins JP, Altman DG, Gotzsche PC, Juni P, Moher D, Oxman AD, Savovic J, Schulz KF, Weeks L, Sterne JA. The Cochrane Collaboration's tool for assessing risk of bias in randomised trials. BMJ. 2011;343:d5928.

15. Assir M, Nasir N, Mansoor H, Waseem T, Ahmed H, Riaz F. Effect of Carica papaya leaf extract on platelet count in dengue fever: a randomized controlled tirals (PLEAD TRIAL). J Allama labal Med Coll. 2011;9:6-9.

16. Yunita F, Hanani E, Kristianto J. The effect of Carica papaya L. leaves extract capsules on platelets count and hematocrit level in dengue fever patient. Int J Med Aromat Plants. 2012;2:573-8.

17. Subenthiran S, Choon TC, Cheong KC, Thayan R, Teck MB, Muniandy PK, Afzan A, Abdullah NR, Ismail Z. Carica papaya leaves juice significantly accelerates the rate of increase in platelet count among patients with dengue fever and dengue Haemorrhagic fever. Evidence-based Complementary and Alternative medicine : eCAM. 2013;2013:616737.

18. Abhishek G, Vinod T, Malik S, Virmani S, Saurabh S. Efficacy of Carica papaya leaf axtract in treating thrombocytopaenia in casesof dengue. Journal Of Advance Researches In Medical Sciences (Formerly Journal of Advance Researches in Biological Sciences). 2015;7(1):01-4.

19. Gowda A, Kumar NV, Kasture P, Nagabhushan K. A pilot study to evaluate the effectiveness of Carica papaya leaf extract in increasing the platelet count in cases of denque with thrombocytopenia. Indian Med Gaz. 2015; 149:109-16.
20. Gadhwal AK, Ankit BS, Chahar C, Tantia P, Sirohi P, Agrawal RP. Effect of Carica papaya leaf extract capsule on platelet count in patients of dengue fever with thrombocytopenia. J Assoc Physicians India. 2016;64(6):22-6.

21. Kasture PN, Nagabhushan $\mathrm{KH}$, Kumar A. A multi-centric, double-blind, placebo-controlled, randomized, prospective study to evaluate the efficacy and safety of Carica papaya leaf extract, as empirical therapy for thrombocytopenia associated with dengue fever. J Assoc Physicians India. 2016;64(6):15-20.

22. Adarsh V, Doddamane K, Kumar VD. Role of carica papaya leaf product in improving the platelet count in patients with dengue fever. Int J Res Med. 2017;6(2):63-8.

23. Srikanth BK, Reddy L, Biradar S, Shamanna M, Mariguddi DD, Krishnakumar M. An open-label, randomized prospective study to evaluate the efficacy and safety of Carica papaya leaf extract for thrombocytopenia associated with dengue fever in pediatric subjects. Pediatric Health Med Ther. 2019;10: $5-11$.

\section{Publisher's Note}

Springer Nature remains neutral with regard to jurisdictional claims in published maps and institutional affiliations.

\section{Ready to submit your research? Choose BMC and benefit from:}

- fast, convenient online submission

- thorough peer review by experienced researchers in your field

- rapid publication on acceptance

- support for research data, including large and complex data types

- gold Open Access which fosters wider collaboration and increased citations

- maximum visibility for your research: over $100 \mathrm{M}$ website views per year

At BMC, research is always in progress.

Learn more biomedcentral.com/submissions 